\title{
Evolution and adaptation of the pandemic A/HINI 2009 influenza virus
}

\author{
This article was published in the following Dove Press journal: \\ Virus Adaptation and Treatment \\ I5 July 20I I \\ Number of times this article has been viewed
}

\author{
Mariette F Ducatez \\ Thomas P Fabrizio \\ Richard J Webby \\ Department of Infectious Diseases, \\ St Jude Children's Research \\ Hospital, Memphis, TN, USA
}

Correspondence: Richard J Webby Department of Infectious Diseases, St Jude Children's Research Hospital, 262 Danny Thomas Place, Memphis,

TN 38105-3678, USA

$\mathrm{Tel}+\mathrm{I} 90 \mid 5953400$

Fax + I 90I 5958559

Email richard.webby@stjude.org
Abstract: The emergence of the $2009 \mathrm{H} 1 \mathrm{~N} 1$ pandemic influenza virus [A(H1N1)pdm09] has provided the public health community with many challenges, but also the scientific community with an opportunity to monitor closely its evolution through the processes of drift and shift. To date, and despite having circulated in humans for nearly two years, little antigenic variation has been observed in the $\mathrm{A}(\mathrm{H} 1 \mathrm{~N} 1) \mathrm{pdm} 09$ viruses. However, as the $\mathrm{A}(\mathrm{H} 1 \mathrm{~N} 1) \mathrm{pdm} 09$ virus continues to circulate and the immunologic pressure within the human population increases, future antigenic change is almost a certainty. Several coinfections of A(H1N1)pdm09 and seasonal A(H1N1) or $\mathrm{A}(\mathrm{H} 3 \mathrm{~N} 2)$ viruses have been observed, but no reassortant viruses have been described in humans, suggesting a lack of fitness of reassortant viruses or a lack of opportunities for interaction of different viral lineages. In contrast, multiple reassortment events have been detected in swine populations between A(H1N1) pdm09 and other endemic swine viruses. Somewhat surprisingly, many of the well characterized influenza virus virulence markers appear to have limited impact on the phenotype of the $\mathrm{A}(\mathrm{H} 1 \mathrm{~N} 1) \mathrm{pdm} 09$ viruses when they have been introduced into mutant viruses in laboratory settings. As such, it is unclear what the evolutionary path of the pandemic virus will be, but the monitoring of any changes in the circulating viruses will remain a global public and animal health priority.

Keywords: influenza, pandemic, evolution, adaptation

\section{Introduction}

The pandemic influenza A(H1N1) 2009 [A(H1N1)pdm09] virus was first isolated in April 2009 in the US, ${ }^{1}$ then spread rapidly throughout the world. Although under review, the World Health Organization definition of an influenza pandemic is the community (human) level outbreak of an animal-derived or an animal-human reassortant influenza virus in multiple areas of the world. The World Health Organization declared the situation a pandemic on June $11,2009,{ }^{2,3}$ a decision that has proven to be the correct one, because the virus has been circulating in humans since. This novel virus originated from a reassortment (see below for an explanation) event between two major lineages of influenza virus known to circulate in global swine populations, ie, a Eurasian swine strain and a US triple reassortant (with gene segments of avian, human, and swine virus origins) strains (Figure 1). Interestingly, only one of these lineages of virus was known to circulate in the Americas, the location where the pandemic virus was first identified. ${ }^{5}$ Because the parental strains were unequivocally of swine origin, the most parsimonious explanation for the genesis of the pandemic virus was that it occurred in pigs. However, because the pandemic virus was never detected in pigs before its emergence in humans, the possibility is left open that the key reassortment event occurred in humans. ${ }^{6}$ Interestingly, bioinformatic analysis suggests that 


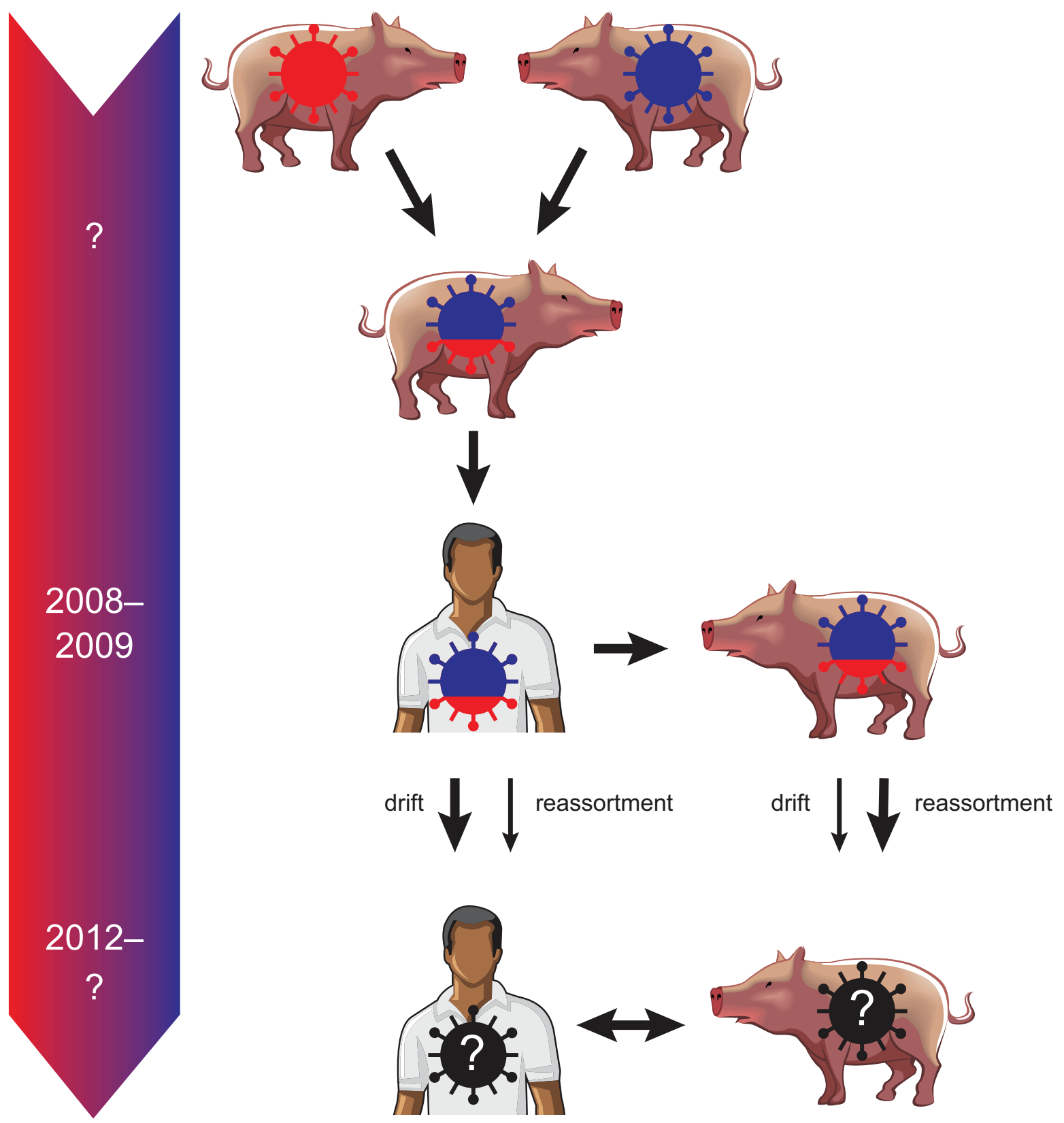

Figure I Current hypothesis in which, prior to the $\mathrm{A}(\mathrm{HINI}) \mathrm{pdm} 09$ virus emergence, a North American swine triple reassortant $\mathrm{HINI}$ virus (blue) reassorted with a European swine HINI virus (red) creating the pandemic strain. In 2008-2009, this reassortant virus emerged in the human population, with subsequent reverse zoonotic transmission back to swine. In each of the human and swine hosts, different immunologic pressures have driven evolution separately. Humans are likely to drive genetic drift while new reassortants have already started to emerge in swine.

the reassortment event occurred a number of years before the strain was first detected. ${ }^{4}$ Although the A(H1N1)pdm09 virus has also been isolated from other hosts such as turkeys ${ }^{7,8}$ and ferrets, ${ }^{9}$ sustained transmission of the virus appears limited to humans and, upon reverse zoonotic transmission, swine.

Influenza viruses have two major molecular mechanisms to evolve and adapt, these being mutation (drift), caused by the inherent infidelity of the viral replication machinery, and by genetic reassortment (shift), caused by the segmented nature of the viral genome. Reassortment can occur upon infection of a single cell by two viruses, where progeny viruses can be generated that contain a mix of gene segments from the parental strains. Both forms of evolution are commonly observed in influenza viruses and both are mechanisms by which the pandemic virus could potentially change. Although these evolutionary mechanisms are in place, without a selection pressure the reasons for the virus to do so are limited. Generally speaking, the two major selective drivers for an 
influenza virus are the immune status of its host population and the adaptation to a new host, both relevant to the pandemic virus. With the exception of the elderly, who had levels of preexisting cross-reactive antibodies to the pandemic virus caused by exposure to antigenically related viruses circulating in the early parts of the 20 th century, ${ }^{10}$ a large portion of the human population was essentially naïve, reducing the host immune pressure on the virus during its first waves in humans. With close to two years of circulation, this situation is now changing, and it is anticipated that the virus will be coming under greater immune selective pressures. ${ }^{11}$ On top of this, the pandemic virus represents an interspecies transmission event, and it is likely that the viral factors that make a virus fine-tuned for swine are not the same as for humans. A close monitoring of $\mathrm{A}(\mathrm{H} 1 \mathrm{~N} 1)$ pdm09 virus evolution is warranted in order to track its changes, which may require adjustment of vaccine and antiviral approaches. Following the trajectory of the virus may also afford insight into the viral factors that govern fitness for the human host. The purpose of this report is to review the current information on the genotypic and phenotypic evolutionary changes that have occurred in the A(H1N1) pdm09 virus upon its adaptation to the human host.

\section{Evolution and adaptation of $A(H I N I) p d m 09$ viruses in human and swine Genetic drift}

As discussed, a fundamental process of evolution and adaptation for influenza viruses is that of mutation. Genetic drift, as discussed, is a result of the infidelity of the viral polymerase combined with pressures from an immune host population. A consequence of this is that the most immunodominant viral proteins are under the most selective pressure and typically drift at the fastest rates. The prototypical example is the immune pressures placed on the viral hemagglutinin protein by neutralizing antibodies generated after infection or vaccination. A virus with an escape mutation in the epitope for a neutralizing antibody is quickly selected for and such mutations are rapidly fixed within a viral population. Accumulation of mutations leads to genetic change in the virus over time, a phenomenon called genetic drift. Indeed, it is the process of genetic drift, particularly in the hemagglutinin protein that allows influenza viruses to escape prior immunity and produce yearly epidemics of disease in humans. The most extensive analysis of genetic drift among the $\mathrm{A}(\mathrm{H} 1 \mathrm{~N} 1) \mathrm{pdm} 09$ viruses has been carried out by laboratories associated with the World Health Organization
Global Influenza Surveillance Network (WHO GISN). The purpose of this network is to monitor changes in circulating human influenza viruses to ensure that the most appropriate viruses are included in the annual influenza vaccines. Presumably because of access to an immunologically naïve host population, little hemagglutinin protein genetic heterogeneity was observed for the first year and a half of the circulation of the $\mathrm{A}(\mathrm{H} 1 \mathrm{~N} 1)$ pdm09 virus. $^{12,13} \mathrm{~A}(\mathrm{H} 1 \mathrm{~N} 1)$ pdm09 hemagglutinin protein genes analyzed as part of the 2011 southern hemisphere vaccine strain selection process, were described as having "increased heterogeneity", a trend that continued into the 2011-2012 northern hemisphere vaccine strain selection process with the formation of "three genetic subgroups". ${ }^{11,14}$

\section{Antigenic variation}

Often associated with genetic drift in the hemagglutinin gene of human influenza viruses in the presence of herd immunity is a concomitant change in viral antigenicity. ${ }^{15}$ Although not necessarily associated with major changes in the phenotypic properties of the virus, the immediate consequence of an antigenic change is a drop in host immunity to the virus and also a reduced efficacy of previously prepared vaccines. De Jong et al showed in 2007 that swine influenza viruses seem to have a slower antigenic evolution than their human counterparts, despite similar genetic evolution rates of their hemagglutinin protein genes. ${ }^{16,17}$ This finding can be attributed to the nature of the host populations, one long-lived with multiple influenza exposures, the other shortlived with few exposures. Therefore, although the number of mutations generated is similar, the viruses in humans are under selective pressure to fix mutations that result in a favorable antigenic change. As discussed above, there has been recent genetic heterogeneity seen among $\mathrm{A}(\mathrm{H} 1 \mathrm{~N} 1) \mathrm{pdm} 09$ viruses, but this has not thus far been associated with the emergence of an antigenically distinct virus cluster. Indeed, the $\mathrm{A}(\mathrm{H} 1 \mathrm{~N} 1)$ pdm09 vaccine virus recommended by WHO GISN in the weeks following the initial 2009 outbreaks, A/California/7/09, still remains antigenically representative and continues to be the recommended vaccine virus for the 2011-2012 influenza season. ${ }^{11,12,14}$ However, as further immunity builds in the human population, it is expected that this situation will change.

\section{Reassortment in humans}

A requirement for genetic reassortment to occur is that at least two viruses must be circulating and infect the same individual. ${ }^{18}$ The fact that the $\mathrm{A}(\mathrm{H} 1 \mathrm{~N} 1) \mathrm{pdm} 09$ viruses 
quickly displaced all other circulating strains when it emerged in 2009 thus has limited chances for reassortment to occur in humans. However, there was a period of a few weeks in some southern hemisphere countries between April and June 2009 when both seasonal and pandemic viruses circulated. ${ }^{19,20} \mathrm{New}$ Zealand and China reported laboratory confirmed cases of coinfection with both the seasonal and pandemic A(H1N1) viruses. ${ }^{19,21,22}$ A case of coinfection with $\mathrm{A}(\mathrm{H} 1 \mathrm{~N} 1)$ pdm09 and seasonal A(H3N2) strains was also observed in Hong Kong. ${ }^{23}$ None of these cases were associated with an unusual or severe clinical presentation, and if reassortant viruses were generated, it appears that they did not circulate to any major degree. The 2010-2011 northern hemisphere influenza season was characterized by an increase in circulation of both $\mathrm{A}(\mathrm{H} 1 \mathrm{~N} 1) \mathrm{pdm} 09$ and $\mathrm{A}(\mathrm{H} 3 \mathrm{~N} 2)$ viruses, so it does appear that the chances for the generation of reassortants are increasing. The potential impact of any such reassortants cannot, unfortunately, be predicted in advance. Because both viruses are already included in the vaccine, any reassortant is unlikely to have a major impact on vaccine efficacy, but the possibility does exist that such reassortants could have more pathogenic properties. Various model systems have been used to test such scenarios, as discussed later in this paper.

\section{Reassortment in swine}

Perhaps of greater concern in the context of reassortment is the likelihood that the $\mathrm{A}(\mathrm{H} 1 \mathrm{~N} 1) \mathrm{pdm} 09$ virus has become endemic in various swine populations following human to swine transmission events. The greater concern here lies in the increased diversity of viruses seen in swine populations. Although it is still not understood what the genetic elements were in the $\mathrm{A}(\mathrm{H} 1 \mathrm{~N} 1) \mathrm{pdm} 09$ virus that allowed it to establish in humans, there is a theoretical concern that antigenically distinct viruses in swine might gain the same ability through reassortment with the pandemic virus. ${ }^{24}$ Swine have also been described as "mixing vessels" for influenza viruses of human and avian origin, because they possess both $\alpha 2,3$ - and $\alpha 2,6$-linked sialic acid receptors. ${ }^{25}$ Avian viruses indeed preferentially bind to $\alpha 2,3$-linked sialic acid while mammalian viruses preferentially bind to $\alpha 2,6$-linked sialic acids. ${ }^{26-28}$ Despite the increased threat being theoretical, there have been a number of descriptions of novel reassortants between $\mathrm{A}(\mathrm{H} 1 \mathrm{~N} 1) \mathrm{pdm} 09$ viruses and various endemic swine viruses. The first of these swine reassortant strains was isolated in Hong Kong: A/swine/Hong Kong/201/2010 contained most gene segments from swine viruses known to circulate in the region, but it had acquired an $\mathrm{A}(\mathrm{H} 1 \mathrm{~N} 1)$ pdm09 neuraminidase gene. ${ }^{24}$ Additionally, in Europe, two pandemic/endemic swine virus reassortants were characterized, one in Italy and another in Germany. ${ }^{29,30}$ Considering the swine ancestry of the pandemic virus, it is not surprising that it can successfully reassort with endemic swine viruses with some frequency and success (Figure 1).

\section{Reassortment in experimental models}

As reviewed above, there is no evidence to suggest that $\mathrm{A}(\mathrm{H} 1 \mathrm{~N} 1) \mathrm{pdm} 09$ viruses have undergone reassortment with seasonal influenza viruses. Several studies have tried to evaluate the likelihood of such reassortant events to occur, as well as the pathogenicity and/or transmissibility of progeny viruses in animal models. ${ }^{31-34}$ Perez et al coinfected ferrets with an $\mathrm{A}(\mathrm{H} 1 \mathrm{~N} 1)$ pdm09 virus and $\mathrm{A}(\mathrm{H} 1 \mathrm{~N} 1)$ or $\mathrm{A}(\mathrm{H} 3 \mathrm{~N} 2)$ seasonal human viruses. The results of this study showed that there was no selective advantage for novel reassortants to be generated in this model system and in fact the A(H1N1) pdm09 virus dominated over both seasonal counterparts. ${ }^{32}$ Two additional teams demonstrated the possibility of reassortment between $\mathrm{A}(\mathrm{H} 1 \mathrm{~N} 1) \mathrm{pdm} 09$ and human seasonal viruses in vitro. In both studies, and in contrast with the earlier work, reassortant progeny viruses were generated, and these turned out to be more virulent than their parental strains in the ferret model. ${ }^{31,33}$ Finally, A(H1N1)pdm09 virus was also shown to be able to reassort with avian $\mathrm{A}(\mathrm{H} 9 \mathrm{~N} 2)$ viruses and to thus evolve toward more pathogenic strains in mice. ${ }^{34}$ The real difficulty with these data lies in their interpretation and extrapolating the results to humans. Nevertheless, the studies do show that successful reassortants can be generated between seasonal and pandemic human viruses, and that the possibility that such events will generate more virulent strains should not be completely discarded.

\section{Replication, transmission, and virulence of pandemic $A(H I N I) p d m 09$ viruses}

As implied earlier, the impact of mutations and reassortment on influenza viruses is not just on the antigenic nature of the virus, but also the phenotypic consequence that they may have. In many respects, the $\mathrm{A}(\mathrm{H} 1 \mathrm{~N} 1)$ pdm09 virus is still a swine influenza virus, and there is some room for the virus to adapt phenotypically to the human host.

\section{Transmission in animal models}

Although, by default, the $\mathrm{A}(\mathrm{H} 1 \mathrm{~N} 1) \mathrm{pdm} 09$ virus is well capable of transmitting in humans, our understanding of the virologic factors involved in the efficiency of spread are far from exhaustive. Consequently, multiple studies ${ }^{35}$ have 
attempted to understand better the mechanisms of efficient viral transmission. In the ferret model, an A(H1N1)pdm09 virus was shown to transmit to direct-contact animals efficiently and, albeit to a lesser degree than seasonal H1N1 viruses, to indirect-contact animals through aerosol droplet transmission. ${ }^{36}$ The lower efficiency of transmission could be interpreted to mean that further changes to the virus would lead to a more infectious disease. Efficient aerosol transmission was observed in chambers with unidirectional airflow. ${ }^{37}$ Subsequent studies by other investigators in different airflow and environmental conditions led to slightly different observations, particularly in regards to the comparative transmission efficiencies of the $\mathrm{A}(\mathrm{H} 1 \mathrm{~N} 1)$ pdm09 and seasonal viruses. ${ }^{38-40}$ In clinical studies, the attack rate among household contacts was found to be similar for pandemic and seasonal influenza viruses, ${ }^{41}$ refuting hypotheses that the former were less than optimized. Supporting this supposition are a number of studies that have looked at known virulence determinants on the transmission of the pandemic virus in animal models. One such study looked at the effect of the hemagglutinin protein D222G mutation that had been associated with virus isolated from the lungs of severe cases and also with passage in in vitro systems. ${ }^{42-45}$ This mutation was shown to alter receptor preferences of the virus, but not transmission properties. ${ }^{46}$ The introduction of molecular markers of virulence into the polymerase basic 2 protein were likewise unable to affect the transmissibility of A(H1N1)pdm09 viruses. ${ }^{47}$ Ramakrishnan et al hypothesized that a truncated polymerase basic 1-F2 (PB1-F2) protein may play a role in enhancing the virus transmission, ${ }^{48}$ but experimental validation of this theory is lacking.

\section{Molecular markers of virulence}

Numerous molecular virulence markers for influenza A viruses have been determined over the years, with factors being identified in all eight gene segments. ${ }^{49}$ In comparison with other influenza subtypes, particularly the highly pathogenic avian viruses, the molecular determinants of virulence for contemporary H1N1 viruses are lacking. ${ }^{35}$ Several residues may play a role in virulence in a subtypespecific manner, such as basic amino acids in the cleavage site of H5 or H7 strains, ${ }^{50}$ but many others likely function across subtypes. Of all viral proteins, the hemagglutinin surface glycoprotein has been the most studied in terms of virulence. The hemagglutinin protein acts as a host determinant factor by binding to sialic acid receptors present on the surface of epithelial cells of hosts. A(H1N1) pdm09 viruses contain the typical human virus-like aspartic acid residues at hemagglutinin protein amino acid locations 190 and 225 which have been shown to code for $\alpha 2,6$ sialic acid preference. ${ }^{5,51}$ Although human virus-like in having $\alpha 2,6$ preference, $\mathrm{A}(\mathrm{H} 1 \mathrm{~N} 1) \mathrm{pdm} 09$ viruses have maintained the receptor binding properties typical of swine viruses, as shown by more sensitive glycan arrays and receptor binding assays. ${ }^{52,53}$ Further adaptation to a more classical human virus-like specificity could theoretically happen in the coming years. To test such hypotheses, two strains of $\mathrm{A}(\mathrm{H} 1 \mathrm{~N} 1) \mathrm{pdm} 09$ virus were passaged nine times in mice to investigate their adaptation potential in a mammalian model. The progeny viruses carried K119N, G155E, S183P, R221K, or D222G hemagglutinin protein mutations and were more virulent than the unpassaged $\mathrm{A}(\mathrm{H} 1 \mathrm{~N} 1) \mathrm{pdm} 09$ virus. ${ }^{54}$ The implications of this study for pathogenesis of the virus in other mammals remains unknown, even though D222G has been associated with increased virulence in humans. ${ }^{42-45}$ However, a reverse genetics hemagglutinin protein D222G A(H1N1)pdm09 mutant was generated and inoculated into ferrets without any increase in virulence. ${ }^{46}$

Similarly to the hemagglutinin protein, the polymerase proteins also play a role in virulence of the influenza viruses. Hai et al and Ozawa et al showed that, unlike what had previously been seen in other viruses, changes in the length of PB1-F2 did not seem to affect the replication or virulence of $\mathrm{A}(\mathrm{H} 1 \mathrm{~N} 1)$ pdm09 virus. ${ }^{55,56}$ The $\mathrm{A}(\mathrm{H} 1 \mathrm{~N} 1)$ pdm09 viruses have a natural truncation of the PB1-F2 protein, but these studies were able to show that restoring its full coding region had little effect. Similarly, positions 627 and 701 in the viral polymerase basic 2 protein, residues shown to affect virulence in other influenza viruses, ${ }^{57-60}$ had no effect in the context of the $\mathrm{A}(\mathrm{H} 1 \mathrm{~N} 1)$ pdm09 viruses. ${ }^{47}$ In mice, some mutations are involved in $\mathrm{A}(\mathrm{H} 1 \mathrm{~N} 1) \mathrm{pdm} 09$ virus virulence, such as polymerase basic 2 protein E158G/A, or polymerase acidic L295P. These mutations occurred upon serial passage in mice and were shown to be responsible for enhanced transcription and replication of the virus. ${ }^{54,61}$

Nonstructural protein 1 is another influenza protein well known to be involved in virulence. A(H1N1)pdm09 viruses possess a truncated nonstructural protein 1 of 220 amino acids. Osawa et al showed that PDZ ligand motifs, RSEV, RSKV, and ESEV, together with W220 in nonstructural protein 1, increased $\mathrm{A}(\mathrm{H} 1 \mathrm{~N} 1)$ pdm09 pathogenicity in mice, although no replication advantage could be observed in vitro. ${ }^{56}$ The same team finally looked at putative synergistic effects of nonstructural protein 1-WRSKV and polymerase basic 2 protein-E627K or polymerase basic 2 protein-D701N on viral replication and could not 
identify any. ${ }^{56}$ In essence, laboratory studies have been unable to identify virulence markers that have marked effects on the $\mathrm{A}(\mathrm{H} 1 \mathrm{~N} 1) \mathrm{pdm} 09$ virus, highlighting the work that needs to be done in this area.

\section{Drivers of future evolution and adaptation}

Despite our inability to identify likely evolutionary paths for A(H1N1)pdm09 virus based on known molecular markers, history tells us to expect changes in the virus. These changes are driven by a number of factors. As A(H1N1)pdm09 virus continues to circulate within the human population and given the inclusion of its antigen into seasonal influenza vaccines, the level of herd immunity will rapidly increase which, in turn, will provide pressure for genetic and antigenic change.

A(H1N1)pdm09 viruses have been postulated to have circulated among swine prior to its emergence in the human population. ${ }^{4}$ Farming practices in swine create a contrasting environment for the virus compared with humans due to the rapid animal turnover. ${ }^{62}$ Such farming practices introduce new naïve hosts several times a year which, in turn, allows spread of the virus with little pressure for antigenic change. ${ }^{63}$ However, once the virus entered humans, it encountered a long-lived host population whose individuals have multiple prior exposures and degrees of immunity providing unique challenges for the virus. ${ }^{64}$ Additionally, other factors such as drug use and vaccination all provide pressures on the virus.

\section{Evolutionary rates}

The retention of some of its swine virus characteristics and the presence of some pre-existing immunity within elderly populations ${ }^{5,65}$ suggests that $\mathrm{A}(\mathrm{H} 1 \mathrm{~N} 1) \mathrm{pdm} 09$ virus would have been under some immediate selective pressures, particularly at key host adaptive and antigenic sites, to change during its early circulation in humans. In order to assess these possibilities, a number of investigators have examined the ratios of nonsynonymous and synonymous nucleotide substitution of the pandemic virus during its first few months of circulation. Sinha et al concluded that all genes exhibited purifying selection with hemagglutinin, neuraminidase, polymerase basic 1 , polymerase basic 2 , polymerase acidic, nucleoprotein, and matrix 1 proteins under "extreme purifying selection". These observations were consistent with what had been seen with triple reassortant swine viruses that were detected in the US in the late 1990s, yet were lower than those observed for seasonal H1N1 viruses between 2001 and $2008 .^{66}$ In contrast with these findings, Furuse et al concluded that the selection pressure on $\mathrm{A}(\mathrm{H} 1 \mathrm{~N} 1) \mathrm{pdm} 09$ viruses was higher than that for H1N1 swine viruses and equivalent to that for H1N1 seasonal virus. Specifically, these authors identified two positions in hemagglutinin protein to be positively selected, ie, positions 206 and 264, the former which is located in an antigenic site. ${ }^{17}$ In 2010, Ding et al analyzed over $700 \mathrm{~A}(\mathrm{H} 1 \mathrm{~N} 1)$ pdm09 hemagglutinin protein sequences and identified two positions under strong positive selection, ie, T220 and E/G239, the latter being involved in receptor binding. ${ }^{67}$ The exact impact of these identified changes is not clear, but has not thus far led to substantial changes in the viruses, as could have been noted by an increase in disease severity or changes in epidemiology.

\section{Vaccination}

By September 15, 2009, four months after the World Health Organization declared the novel H1N1 a pandemic, the US Food and Drug Administration had granted approval for vaccine release. ${ }^{68}$ Although a very commendable effort considering the pressures of the vaccine production systems and the poor growth of early vaccine candidate viruses, the declaration of a pandemic implied that the virus was already widespread in most countries and that the epidemic curve was well and truly underway by the time mass vaccination campaigns started. Because the currently licensed vaccines work primarily through induction of neutralizing antibodies that target the hemagglutinin protein, ${ }^{69}$ vaccination also has a theoretical risk of driving antigenic drift in the virus. Considering the global vaccine coverage, ${ }^{70-76}$ it is likely that natural infection has played a larger role in driving viral change than vaccination to date. In the US, one of the countries with the highest influenza vaccine coverage, for example, it was estimated that only $20 \%$ of the population had received the 2009 pandemic H1N1 monovalent vaccine by early $2010 .{ }^{77}$

\section{Antiviral drug use}

A major limitation of the most widely used anti-influenza drugs, ie, the ion channel blockers (amantadines) and the neuraminidase inhibitors (oseltamivir and zanamivir), is that they are susceptible to minor changes in the virus. Indeed, single amino acid changes in the matrix 2 and neuraminidase proteins can confer resistance to the ion channel blockers and neuraminidase inhibitor classes of drug, respectively. ${ }^{18}$ Because the $\mathrm{A}(\mathrm{H} 1 \mathrm{~N} 1)$ pdm09 viruses were already resistant to amantadines upon entry into the human population, ${ }^{5}$ oseltamivir and zanamivir were by far the most commonly prescribed drugs to treat infected individuals and close contacts of infected persons. A number of reports of a known mutation in neuraminidase 
associated with resistance to the neuraminidase inhibitor oseltamivir were made. Most of these reports were made in immunocompromised treated individuals or in individuals who were prophylactically treated with suboptimal doses of drug. ${ }^{78}$ Although there is some considerable concern that the $\mathrm{A}(\mathrm{H} 1 \mathrm{~N} 1) \mathrm{pdm} 09$ viruses will evolve into an oseltamivir-resistant population as their seasonal H1N1 counterpart did through fixation of these mutations, this has so far not occurred. Nevertheless, the monitoring of antiviral drug resistance remains a key facet of the WHO GISN system.

\section{Conclusion}

The emergence of the pandemic virus in 2009 has offered a unique opportunity to follow the evolution of a new human pathogen in real time. The available molecular tools and the number of investigators with access to them will provide substantial detail on the evolutionary path of the A(H1N1) pdm09 viruses. Without doubt, we will learn much about the process of influenza virus evolution. Not only do we have the opportunity to follow the changes in the virus generated from circulation in humans, but the virus is also clearly endemic in at least some swine populations (following reverse zoonoses) allowing for a mother nature-made comparative study of the impact of host on viral change. With a little under two years of circulation of the virus to date, only subtle changes have been observed in the virus in humans. As expected, there is evidence building for the accumulation of some genetic variation in the virus, but this variation has so far not led to the emergence of an antigenically or phenotypically different virus population. In swine, the changes in the virus have been more dramatic with a number of different reassortant viruses having been identified. However, it does appear, that similarly to the situation in humans, what genetic changes there have been have not been accompanied by major changes in the biology of the virus. The major question of course remains as to what the virus will do in the future. Everything we know about influenza viruses tells us that the virus will change in humans, and that this change will be accompanied by antigenic drift, necessitating vaccine changes, and that these changes will likely occur sooner rather than later. These expected events are, however, what the WHO GISN was developed for and they will be dealt with in the same way as for changes in seasonal influenza viruses. Perhaps of greater concern than simply antigenic change would be a change in viral virulence. Again, although history tells us that there will be considerable variation in the morbidity and mortality associated with seasonal epidemics caused by future variants of $\mathrm{A}(\mathrm{H} 1 \mathrm{~N} 1) \mathrm{pdm} 09$ viruses, it also suggests that we will not see major changes in the way this virus behaves without substantial genetic changes. The presence of this virus in swine, the propensity for swine to support reassortment, and the known ability, albeit limited, of viruses to move between swine and humans, create an opportunity for these substantial changes to occur. The emergence of this virus came as a surprise to global public health, and until we understand more about the mechanisms of influenza pathogenesis, only time will tell us if there are more to come.

\section{Acknowledgments}

The authors' working laboratories are funded in part by the National Institute Allergy and Infectious Diseases, National Institutes of Health, and by the American Lebanese Syrian Associated Charities. We thank Julie Groff (St Jude Children's Research Hospital) for graphic assistance.

\section{Disclosure}

The authors report no conflicts of interest in this work.

\section{References}

1. Outbreak of swine-origin influenza $\mathrm{A}(\mathrm{H} 1 \mathrm{~N} 1)$ virus infection - Mexico, March-April 2009. MMWR Morb Mortal Wkly Rep. 2009;58: 467-470.

2. Gibbs AJ, Armstrong JS, Downie JC. From where did the 2009 'swineorigin' influenza A virus (H1N1) emerge? Virol J. 2009;6:207.

3. Pascua PN, Song MS, Lee JH, et al. Evaluation of the efficacy and crossprotectivity of recent human and swine vaccines against the pandemic (H1N1) 2009 virus infection. PLoS One. 2009;4:e8431.

4. Smith GJ, Vijaykrishna D, Bahl J, et al. Origins and evolutionary genomics of the 2009swine-origin H1N1 influenza A epidemic. Nature. 2009;459:1122-1125.

5. Garten RJ, Davis CT, Russell CA, et al. Antigenic and genetic characteristics of swine-origin 2009 A(H1N1) influenza viruses circulating in humans. Science. 2009;325:197-201.

6. Ducatez MF, Hause B, Stigger-Rosser E, et al. Multiple reassortment of endemic swine and pandemic A/H1N1 (2009) influenza viruses in swine herds in the United States. Emerging Infectious Diseases. 2011. [Epub ahead of press.]

7. Berhane Y, Ojkic D, Neufeld J, et al. Molecular characterization of pandemic H1N1 influenza viruses isolated from turkeys and pathogenicity of a human pH1N1 isolate in turkeys. Avian Dis. 2010;54: $1275-1285$.

8. Mathieu C, Moreno V, Retamal P, et al. Pandemic (H1N1) 2009 in breeding turkeys, Valparaiso, Chile. Emerg Infect Dis. 2010;16:709-711.

9. Swenson SL, Koster LG, Jenkins-Moore M, et al. Natural cases of 2009 pandemic H1N1 influenza A virus in pet ferrets. $J$ Vet Diagn Invest. 2010;22:784-788.

10. Hancock K, Veguilla V, Lu X, et al. Cross-reactive antibody responses to the 2009 pandemic H1N1 influenza virus. N Engl J Med. 2009;361: $1945-1952$.

11. No authors listed. Recommended composition of influenza virus vaccines for use in the 2011-2012 northern hemisphere influenza season. Wkly Epidemiol Rec. 2011;86:86-90.

12. No authors listed. Recommended viruses for influenza vaccines for use in the 2010-2011 northern hemisphere influenza season. Wkly Epidemiol Rec. 2010;85:81-92. 
13. No authors listed. Recommended composition of influenza virus vaccines for use in the 2010 influenza season (southern hemisphere winter). Wkly Epidemiol Rec. 2009;84:421-431.

14. No authors listed. Recommended viruses of influenza vaccines for use in the 2011 influenza season (southern hemisphere). Wkly Epidemiol Rec. 2010;85:402-412.

15. Carrat F, Flahault A. Influenza vaccine: The challenge of antigenic drift. Vaccine. 2007;25:6852-6862.

16. De Jong JC, Smith DJ, Lapedes AS, et al. Antigenic and genetic evolution of swine influenza A(H3N2) viruses in Europe. J Virol. 2007;81:4315-4322.

17. Furuse Y, Shimabukuro K, Odagiri T, et al. Comparison of selection pressures on the HA gene of pandemic (2009) and seasonal human and swine influenza AH1 subtype viruses. Virology. 2010;405: 314-321.

18. Wright PF, Neumann G, Kawaoka Y. Orthomyxoviruses. In: Knipe DM, Howley PM, editors. Fields Virology. Vol 2. Philadelphia, PA: Lippincott Williams and Wilkins; 2007.

19. Peacey M, Hall RJ, Sonnberg S, et al. Pandemic (H1N1) 2009 and seasonal influenza A (H1N1) co-infection, New Zealand, 2009. Emerg Infect Dis. 2010;16:1618-1620.

20. World Health Organization [homepage on the Internet]. Global Health Atlas; c2003-2007. Available from: http://apps.who.int/globalatlas/ dataQuery/. Accessed June 16, 2011.

21. Ducatez MF, Sonnberg S, Hall RJ, et al. Genotyping assay for the identification of 2009-2010 pandemic and seasonal H1N1 influenza virus reassortants. J Virol Methods. 2010;168:78-81.

22. Janies DA, Voronkin IO, Studer J, et al. Selection for resistance to oseltamivir in seasonal and pandemic H1N1 influenza and widespread co-circulation of the lineages. Int J Health Geogr. 2010;9:13.

23. Lee N, Chan PK, Lam WY, Szeto CC, Hui DS. Co-infection with pandemic H1N1 and seasonal H3 N2 influenza viruses. Ann Intern Med. 2010;152:618-619.

24. Vijaykrishna D, Poon LL, Zhu HC, et al. Reassortment of pandemic H1N1/2009 influenza A virus in swine. Science. 2010;328:1529.

25. Webster RG, Sharp GB, Claas EC. Interspecies transmission of influenza viruses. Am J Respir Crit Care Med. 1995;152(4 Pt 2):S25-S30.

26. Couceiro JN, Paulson JC, Baum LG. Influenza virus strains selectively recognize sialyloligosaccharides on human respiratory epithelium; the role of the host cell in selection of hemagglutinin receptor specificity. Virus Res. 1993;29:155-165.

27. Rogers GN, Paulson JC. Receptor determinants of human and animal influenza virus isolates: Differences in receptor specificity of the $\mathrm{H} 3$ hemagglutinin based on species of origin. Virology. 1983;127:361-373.

28. Ito T, Couceiro JN, Kelm S, et al. Molecular basis for the generation in pigs of influenza A viruses with pandemic potential. J Virol. 1998;72: 7367-7373.

29. Moreno A, Di Trani L, Faccini S, et al. Novel H1N2 swine influenza reassortant strain in pigs derived from the pandemic H1N1/2009 virus. Vet Microbiol. 2011;149:472-477.

30. Starick E, Lange E, Fereidouni S, et al. Re-assorted pandemic (H1N1) 2009 influenza A virus discovered from pigs in Germany. J Gen Virol. 2011;92(Pt 5):1184-1188

31. Ilyushina NA, Ducatez MF, Rehg JE, et al. Does pandemic A/H1N1 virus have the potential to become more pathogenic? MBio. 2010;1: e00247-e00210.

32. Perez DR, Sorrell E, Angel M, et al. Fitness of pandemic H1N1 and seasonal influenza A viruses during co-infection: Evidence of competitive advantage of pandemic H1N1 influenza versus seasonal influenza. PLoS Curr. 2009;1:RRN1011.

33. Schrauwen EJ, Herfst S, Chutinimitkul S, et al. Possible increased pathogenicity of pandemic (H1N1) 2009 influenza virus upon reassortment. Emerg Infect Dis. 2010;17:200-208.

34. Sun Y, Qin K, Wang J, et al. High genetic compatibility and increased pathogenicity of reassortants derived from avian H9N2 and pandemic H1N1/2009 influenza viruses. Proc Natl Acad Sci U S A. 2011;108: 4164-4169.
35. Belser JA, Maines TR, Tumpey TM, Katz JM. Influenza A virus transmission: Contributing factors and clinical implications. Expert Rev Mol Med. 2010;12:e39.

36. Maines TR, Jayaraman A, Belser JA, et al. Transmission and pathogenesis of swine-origin $2009 \mathrm{~A}(\mathrm{H} 1 \mathrm{N1})$ influenza viruses in ferrets and mice. Science. 2009;325:484-487.

37. Munster VJ, de Wit E, van den Brand JM, et al. Pathogenesis and transmission of swine-origin $2009 \mathrm{~A}(\mathrm{H} 1 \mathrm{~N} 1)$ influenza virus in ferrets. Science. 2009;325:481-483.

38. Duan S, Boltz DA, Seiler P, et al. Oseltamivir-resistant pandemic H1N1/2009 influenza virus possesses lower transmissibility and fitness in ferrets. PLoS Pathog. 2010;6:e1001022.

39. Seibert CW, Kaminski M, Philipp J, et al. Oseltamivir-resistant variants of the 2009 pandemic H1N1 influenza A virus are not attenuated in the guinea pig and ferret transmission models. $J$ Virol. 2010;84:11219-11226

40. Steel J, Palese P, Lowen AC. Transmission of a 2009 pandemic influenza virus shows a sensitivity to temperature and humidity similar to that of an H3N2 seasonal strain. J Virol. 2010;85:11400-11402.

41. Cowling BJ, Chan KH, Fang VJ, et al. Comparative epidemiology of pandemic and seasonal influenza A in households. $N$ Engl J Med. 2010;362:2175-2184

42. Rogers F. Helping patients to live with ankylosing spondylitis. Practitioner. 1983;227:1187-1189.

43. Ikonen N, Haanpaa M, Ronkko E, et al. Genetic diversity of the 2009 pandemic influenza $\mathrm{A}(\mathrm{H} 1 \mathrm{~N} 1)$ viruses in Finland. PLoS One. 2010;5:e13329.

44. Ledesma J, Pozo F, Ruiz MP, et al. Substitutions in position 222 of haemagglutinin of pandemic influenza A (H1N1) 2009 viruses in Spain. J Clin Virol. 2011;51:75-78.

45. Puzelli S, Facchini M, De Marco MA, et al. Molecular surveillance of pandemic influenza $\mathrm{A}(\mathrm{H} 1 \mathrm{~N} 1)$ viruses circulating in Italy from May 2009 to February 2010: Association between haemagglutinin mutations and clinical outcome. Euro Surveill. 2010;15:19696.

46. Chutinimitkul S, Herfst S, Steel J, et al. Virulence-associated substitution $\mathrm{D} 222 \mathrm{G}$ in the hemagglutinin of 2009 pandemic influenza $\mathrm{A}(\mathrm{H} 1 \mathrm{~N} 1)$ virus affects receptor binding. J Virol. 2010;84:11802-11813.

47. Herfst $\mathrm{S}$, Chutinimitkul S, Ye J, et al. Introduction of virulence markers in PB2 of pandemic swine-origin influenza virus does not result in enhanced virulence or transmission. J Virol. 2010;84:3752-3758.

48. Ramakrishnan MA, Gramer MR, Goyal SM, Sreevatsan S. A serine12Stop mutation in PB1-F2 of the 2009 pandemic (H1N1) influenza A: A possible reason for its enhanced transmission and pathogenicity to humans. J Vet Sci. 2009;10:349-351.

49. Horimoto T, Kawaoka Y. Influenza: Lessons from past pandemics, warnings from current incidents. Nat Rev Microbiol. 2005;3: 591-600.

50. US Animal Health Association. Report of the Committee on Transmissible Diseases of Poultry and other Species. Criteria for determining that AI virus isolation causing an outbreak must be considered for eradication. Paper presented at the 98th annual meeting of the US Animal Health Association, October 29-November 4, 1994, Grand Rapids, MI.

51. Tscherne DM, Garcia-Sastre A. Virulence determinants of pandemic influenza viruses. J Clin Invest. 2011;121:6-13.

52. Chen LM, Rivailler P, Hossain J, et al. Receptor specificity of subtype $\mathrm{H} 1$ influenza A viruses isolated from swine and humans in the United States. Virology. 2010;412:401-410.

53. Ilyushina NA, Kim JK, Negovetich NJ, et al. Extensive mammalian ancestry of pandemic (H1N1) 2009 virus. Emerg Infect Dis. 2010;16: 314-317.

54. Ilyushina NA, Khalenkov AM, Seiler JP, et al. Adaptation of pandemic H1N1 influenza viruses in mice. J Virol. 2010;84:8607-8616.

55. Hai R, Schmolke M, Varga ZT, et al. PB1-F2 expression by the 2009 pandemic H1N1 influenza virus has minimal impact on virulence in animal models. J Virol. 2010;84:4442-4450. 
56. Ozawa M, Basnet S, Burley LM, Neumann G, Hatta M, Kawaoka Y. Impact of amino acid mutations in PB2, PB1-F2, and NS1 on the replication and pathogenicity of pandemic (H1N1) 2009 influenza viruses. J Virol. 2011;85:4596-4601.

57. Gabriel G, Dauber B, Wolff T, Planz O, Klenk HD, Stech J. The viral polymerase mediates adaptation of an avian influenza virus to a mammalian host. Proc Natl Acad Sci U S A. 2005;102:18590-18595.

58. Gao Y, Zhang Y, Shinya K, et al. Identification of amino acids in HA and PB2 critical for the transmission of $\mathrm{H} 5 \mathrm{~N} 1$ avian influenza viruses in a mammalian host. PLoS Pathog. 2009;5:e1000709.

59. Li Z, Chen H, Jiao P, et al. Molecular basis of replication of duck H5N1 influenza viruses in a mammalian mouse model. J Virol. 2005; 79:12058-12064.

60. Steel J, Lowen AC, Mubareka S, Palese P. Transmission of influenza virus in a mammalian host is increased by $\mathrm{PB} 2$ amino acids $627 \mathrm{~K}$ or 627E/701 N. PLoS Pathog. 2009;5:e1000252.

61. Zhou B, Li Y, Halpin R, Hine E, Spiro DJ, Wentworth DE. PB2 residue 158 is a pathogenic determinant of pandemic-H1N1 and H5 influenza A viruses in mice. J Virol. 2011;85:357-365.

62. Brown D. Back where virus started, new scrutiny of pig farming. The Washington Post. October 25, 2009.

63. Brookes SM, Nunez A, Choudhury B, et al. Replication, pathogenesis and transmission of pandemic (H1N1) 2009 virus in non-immune pigs. PLoS One. 2010;5:e9068.

64. Cohen J. Swine flu pandemic. What's old is new: 1918 virus matches 2009 H1N1strain. Science. 2010;327:1563-1564.

65. Itoh Y, Shinya K, Kiso M, et al. In vitro and in vivo characterization of new swine-origin H1N1 influenza viruses. Nature. 2009;460: 1021-1025.

66. Sinha NK, Roy A, Das B, Das S, Basak S. Evolutionary complexities of swine flu H1N1 gene sequences of 2009. Biochem Biophys Res Commun. 2009;390:349-351.

67. Ding X, Jiang L, Ke C, et al. Amino acid sequence analysis and identification of mutations under positive selection in hemagglutinin of 2009 influenza A(H1N1) isolates. Virus Genes. 2010;41:329-340.

68. Centers for Disease Control and Prevention. Update on influenza A (H1N1) 2009 monovalent vaccines. MMWR Morb Mortal Wkly Rep. 2009;58:1100-1101.
69. Ellebedy AH, Webby RJ. Influenza vaccines. Vaccine. 2009;27 Suppl 4:D65-D68.

70. Tuppin P, Samson S, Weill A, Ricordeau P, Allemand H. Seasonal influenza vaccination coverage in France during two influenza seasons (2007 and 2008) and during a context of pandemic influenza A(H1N1) in 2009. Vaccine. May 6, 2011. [Epub ahead of print].

71. Walter D, Bohmer MM, Heiden MA, Reiter S, Krause G, Wichmann O. Monitoring pandemic influenza $\mathrm{A}(\mathrm{H} 1 \mathrm{~N} 1)$ vaccination coverage in Germany 2009/10 - Results from thirteen consecutive cross-sectional surveys. Vaccine. 2011;29:4008-4012.

72. Vaux S, Van Cauteren D, Guthmann JP, et al. Influenza vaccination coverage against seasonal and pandemic influenza and their determinants in France: A cross-sectional survey. BMC Public Health. 2011;11:30.

73. Rodriguez-Rieiro C, Esteban-Vasallo MD, Dominguez-Berjon MF, et al. Coverage and predictors of vaccination against 2009 pandemic H1N1 influenza in Madrid, Spain. Vaccine. 2011;29:1332-1338.

74. Kwon Y, Cho HY, Lee YK, Bae GR, Lee SG. Relationship between intention of novel influenza $\mathrm{A}(\mathrm{H} 1 \mathrm{~N} 1)$ vaccination and vaccination coverage rate. Vaccine. 2010;29:161-165.

75. Mak DB, Daly AM, Armstrong PK, Effler PV. Pandemic (H1N1) 2009 influenza vaccination coverage in Western Australia. Med J Aust. 2010;193:401-404.

76. Centers for Disease Control and Prevention. Interim results: Statespecific seasonal influenza vaccination coverage - United States, August 2009-January 2010. MMWR Morb Mortal Wkly Rep. 2010;59: $477-484$.

77. Centers for Disease Control and Prevention. Interim results: Influenza A(H1N1) 2009 monovalent vaccination coverage - United States, October-December 2009. MMWR Morb Mortal Wkly Rep. 2010;59: 44- 48 .

78. Update on oseltamivir-resistant pandemic A(H1N1) 2009 influenza virus: January 2010. Wkly Epidemiol Rec. 2009;85:37-40.
Virus Adaptation and Treatment

\section{Publish your work in this journal}

Virus Adaptation and Treatment is an international, peer-reviewed open access journal focusing on the study of virology, viral adaptation and the development and use of antiviral drugs and vaccines to achieve improved outcomes in infection control and treatment. The journa welcomes original research, basic science, clinical \& epidemiological

\section{Dovepress}

studies, reviews \& evaluations, expert opinion and commentary, case reports and extended reports. The manuscript management system is completely online and includes a very quick and fair peer-review system, which is all easy to use. Visit http://www.dovepress.com/ testimonials.php to read real quotes from published authors. 